\title{
História oral e empresas: reflexões a partir do Museu da Pessoa
}

\author{
Ian Kisil Marino* \\ ORCID iD 0000-0002-6584-834X \\ Universidade Estadual de Campinas, Instituto de Letras e Ciências \\ Humanas, Departamento de História, Campinas, Brasil
}

\begin{abstract}
Resumo: Este artigo discute a intersecçáo entre a história oral e a história empresarial a partir do projeto Educar para o futuro, encomendado pela Fundação Bradesco ao Instituto Museu da Pessoa. Os procedimentos historiográficos dessa instituição identificam-se com a história oral, alimentando uma retórica de empoderamento comunitário a partir da constituição de acervos e narrativas compostos por depoimentos orais. Simultaneamente, o Instituto presta serviços a empresas, atendendo a demandas e contingências por vezes divergentes das historiográficas. Dada a consolidação de um mercado de histórias empresariais sob encomenda no Brasil nas últimas duas décadas - no qual a história oral ocupa um espaço importante -, como avaliar as possibilidades e os limites para a prática historiográfica? O caso observado é paradigmático, provendo substratos para melhor se compreender as implicaçôes teóricas e metodológicas da intersecção entre história oral e empresas no Brasil.
\end{abstract}

Palavras-chave: História oral. História empresarial. História pública.

\section{Oral history and business: reflections based on Museu da Pessoa}

Abstract: This article discusses the intersection between oral history and business history based on the project Educar para of futuro [Educating for the future], ordered by the Bradesco Foundation to Museu da Pessoa Institute. The historiographical practice of the latter identifies with oral history, reinforcing the idea of community empowerment as a result of archives and narratives compounded by oral testimonies. At the same time, the Institute renders historiographical service to companies, which leads to new demands and contingencies that may differ from historiographic parameters. Bearing in mind the consolidation of a market for business history on demand in Brazil over the last two decades - in which oral history

Doutorando em História pela Universidade Estadual de Campinas (Unicamp). E-mail: iankmarino@ gmail.com. 
has taken up an important space - how should the possibilities and restraints of the historiographical practice be assessed? The case of Museu da Pessoa is paradigmatic and provides the grounds for a better understanding about theoretical and methodological implications of the intersection between oral history and companies in Brazil.

Keywords: Oral history. Business history. Public history.

"Qual é o compromisso do pesquisador de história oral? Atender ao cliente que pagou pelos serviços que contratou, ou manter seus princípios éticos de trabalhar por uma maior democratização da sociedade?”, perguntou-se Marieta Ferreira (1998, p. 10), após constatar que a "história oral empresarial" compunha uma das "três grandes linhas de trabalho" que se abriam à história oral no Brasil nos anos 1990. Esse questionamento persiste, embora os indícios de um campo de trabalho de outrora encontrem-se consideravelmente mais firmes hoje. Já existe uma multiplicidade de livros, acervos, centros de memória e exposiçôes organizados por empresas, com associaçôes e pensadores empresariais acostumados a tratar da história como um campo quase seu. Proliferam-se também organizaçôes e historiadores individuais trabalhando sob contrato com empresas, por gosto ou pela imposição empregatícia de tempos em que a pesquisa e o ensino se veem carentes de postos e incentivos. Aumentaram as interfaces de trabalho com empresas para a história oral, com resultados diversos, como livros, materiais audiovisuais e o incremento de acervos de depoimentos de trabalhadores de ramos variados.

Este texto inspira-se no questionamento de Ferreira para, mais de duas décadas depois, contemplar a relação entre história oral e empresas. Busca-se caracterizar as circunstâncias envolvidas na ocasião da ascensão da história empresarial no Brasil para compreender o lugar da história oral nesse processo. Para tal, propóe-se uma crítica empírica do projeto Educar para o futuro, realizado pelo Instituto Museu da Pessoa sob contrato da Fundação Bradesco, em 2006. Com ênfase nas entrevistas, sugere-se um estudo que, embora particular, possa contribuir com a caracterização do campo como um todo, dada a relevância da organizaçấo imbuída da realização do projeto. Com efeito, a avaliaçáo do caso selecionado pode contribuir não somente com o aperfeiçoamento dos critérios contemplativos da história oral empresarial, mas também com o entendimento das circunstâncias do trabalho sob contrato para historiadores no século XXI. Inicialmente, o campo da história empresarial será brevemente discutido, destacando o lugar da história oral nesse meio no Brasil e encaminhando o olhar ao Museu da Pessoa; na sequência, serão abordadas as operaçóes historiográficas do projeto da Fundação Bradesco, com ênfase nos procedimentos metodológicos de entrevista; por fim, serão propostas contribuiçóes à caracterização tanto da história oral sob encomenda quanto do trabalho sob contrato empresarial para historiadores. 


\section{História empresarial e história oral}

A história empresarial é um campo de múltiplas faces. Sua consolidação acadêmica remete a escolas de negócios estadunidenses na década de 1920, com predominância de economistas e historiadores econômicos e um paradigma historiográfico de caráter institucional e liberal (Gonçalves; Saes, 2017). A obra de Alfred Chandler, nas décadas de 1950 a 1970, foi um marco na reformulação e na difusão da área a nível internacional, na medida em que incentivou estudos comparados com um olhar macroeconômico e, principalmente, elegeu o estudo da estrutura administrativa como parâmetro central da historiografia empresarial (Jones, 2017). Nas décadas de 1970 e 1980, diferentes impulsos historiográficos pluralizaram o estudo de empresas: a nova história, por exemplo, deslocou-as ao campo cultural, abrindo a dimensão identitária e simbólica a um objeto até então restritamente econômico e administrativo (Tonini; Gagette, 2004); a história pública, por outro lado, com o anseio de incrementar o leque de opçóes profissionais a historiadores e legitimar sua atuação nesses meios, encontrou nas empresas um agente importante (Mendes, 2010). Não à toa, um número inteiro dos primórdios do famoso periódico The Public Historian é especialmente dedicado ao tema; ${ }^{1}$ no Brasil, a história empresarial compôs tanto o programa do evento seminal Curso de Introdução à História Pública, em 2011, quanto um capítulo no estreante livro Introdução à História Pública (2011), assinado por Paulo Nassar. As empresas seriam um potencial espaço de trabalho para historiadores, na organizaçáo de acervos e exposiçôes, na realização de projetos de pesquisa e na redação de livros (Forman, 1981).

Como assinalou Ricardo Santhiago (2011, p. 97), "a história oral é provavelmente o ramo do conhecimento histórico que mais e melhor se associou à história pública". Assim, esse outro campo, também muito plural, viu crescer para si uma esfera de atuaçáo relativamente nova no país na década de 1990. O impulso de institucionalização do Centro de Pesquisa e Documentação da Fundação Getúlio Vargas (CPDOC-FGV) especializara-se na construção de acervos de depoimentos orais de elites políticas, econômicas e militares brasileiras desde 1975, mas a priori não se trabalhava sob encomenda (Alberti, 1996b). No processo de redemocratizaçáo dos anos 1980, ganharam força iniciativas de movimentos sociais com militância democrática e inclusiva, enfatizando a história oral de marginalizados - um esforço que ganhou corpo com pesquisadores acadêmicos nas décadas seguintes (Ferreira, 1998). Apenas nos anos 1990 tornou-se mais comum que empresas contratassem projetos de história oral. Estes, por sua vez, correspondiam à "necessidade de complementar seu orçamento" do CPDOC, por exemplo (Alberti, 1996b, p. 4) - ou à oportunidade de um mercado em ascensão para "'agências' de historiadores especializados" (Tonini; Gagette, 2004, p. 116-117). O "mercado de memórias" de empresas, enfim, abria-se definitivamente para

Trata-se do volume 3, do verão de 1981. 
a história oral no Brasil, segundo Verena Alberti (1996b, p. 4).

Mas por que as empresas começaram a se interessar pela história? A resposta não se constrói somente observando debates historiográficos. No decorrer das décadas de 1980 e 1990, com o aumento da competitividade resultante da privatizaçáo de empresas estatais, da austeridade fiscal, da internacionalização, dentre outras medidas, reformularam-se alguns princípios gerenciais que incrementaram o interesse de empresas pelo que a história poderia oferecer - ou pelo que se acreditava que a história ofereceria. Esta seria uma ferramenta de autorreflexão e legitimidade, para identificar erros e acertos do passado e lidar com crises identitárias, segundo Paulo Nassar (2004). A organizaçáo de eventos, a publicaçáo de manuais, livros e artigos e a especificação da história empresarial entre os prêmios anuais da Associação Brasileira de Comunicação Empresarial (Aberje) - presidida por Nassar a partir de 1999 - consolidaram a proximidade entre história e empresas. ${ }^{2}$ Tratar-se-ia de uma ferramenta de criaçáo de identidade e as empresas estruturaram fundamentos para se "servir da história para legitimar-se" (Santos, 2014, p. 68).

Nesse movimento, a história oral teve lugar privilegiado. No II Encontro Internacional de Museus Empresariais da Aberje, em 2000, o palestrante principal foi Paul Thompson, expoente da história oral inglesa identificado com uma escola cujo foco se direcionava não às elites, mas às camadas populares, como enunciavam livros do autor desde os anos 1960. Não parecia ser uma história oral das elites, portanto, que interessava às empresas, mas uma "história oral vista de baixo", pelos funcionários que as construíam. Segundo Antonio Carlos Saliba, presidente da Janssen-Cilag, quando a empresa contratou o projeto de história oral resultante no livro Farma: uma constante construção (1996), "a História de uma empresa pode ser registrada de várias formas. Nós escolhemos a mais difícil, mas certamente muito rica: a história a partir da narração das pessoas envolvidas em sua construção" (apud Worcman, 2004, p. 25). Na mesma linha foi o discurso de Thompson no referido evento: "quando uma companhia ouve seus funcionários e clientes, tem que ser corajosa o suficiente para encarar as respostas. Geralmente as histórias que as empresas contam de si mesmas são muito brandas e glorificadoras. A história oral pode acrescentar mais visóes" (apud Nassar, 2004, p. 17).

Nos anos 1990, além do trabalho já consolidado do CPDOC, surgiram organizaçóes especializadas em serviços históricos, a fim de suprir essa nova demanda empresarial. Uma das principais - e especialista em história oral - foi o Museu da Pessoa, fundado em 1991, em Sáo Paulo. ${ }^{3}$ Inspirado nos anseios de empoderamento narrativo

2 O I Encontro Internacional de Museus Empresariais da Aberje ocorreu em 1999, com a participação de grandes empresas, como Telefônica, Vale, Brasmotor, Odebrecht, Garoto e organizações especializadas em serviços históricos, como Memória \& Identidade, Museu da Pessoa e Fundação Patrimônio Histórico da Energia de São Paulo.

3 O Instituto é protagonista entre outras organizações no Brasil, como Memória \& Identidade e Grifo, por exemplo. Embora não caiba aqui um detalhamento, há nuances importantes que diferenciam essas 
da história oral - "a história de toda e qualquer pessoa tem valor e deve ser considerada parte da memória social” (Worcman, 2017, p. 3) -, o Museu se comprometeu com a criação de um acervo significativo de acesso público, a partir de duas vertentes: histórias de vida de voluntários interessados nesse registro e projetos de memória organizacional sob contrato. Esses projetos, além de financiarem a ascensão do Museu, produziram arquivos, exposiçóes e livros (Worcman; Pereira, 2006).

$\mathrm{Na}$ trajetória do Museu da Pessoa, a temática da intervenção social tornouse cada vez mais importante, e a instituição conquistou o caráter de Organização da Sociedade Civil de Interesse Público (Oscip), em 2002. Com isso, o Instituto - como passou a denominar-se - afinou seu enquadramento aos preceitos de intervençáo social do chamado terceiro setor, aproximando-se de Organizaçôes Não Governamentais (ONGs), fundaçôes empresariais e associaçôes civis de impacto social. Recebendo aportes financeiros de programas de incentivo à cultura e preservação do patrimônio, o Museu progrediu: atualmente, seu acervo possui mais de vinte mil depoimentos e seu portfólio conta com mais de duzentos projetos organizacionais realizados a grandes empresas, como Camargo Corrêa, Bradesco, Grupo Algar, Votorantim e Petrobras (Museu da Pessoa, 2019).

"A história de uma empresa não deve ser pensada apenas como resgate do passado", comentou a fundadora e diretora do Museu da Pessoa, Karen Worcman (2004, p. 23), "mas como marco referencial a partir do qual as pessoas redescobrem valores e experiências, reforçam vínculos presentes, criam empatia com a trajetória da organização e podem refletir sobre as expectativas dos planos futuros". A princípio, essa percepçáo casa com os anseios empresariais sobre o uso da história oral. Assim, o Museu assume que seus projetos devem partir da motivação da instituiçáo contratante: os interesses em contar sua história, as fontes disponíveis, potenciais leitores e a divulgaçáo são aspectos norteadores desses trabalhos (Worcman; Pereira, 2006, p. 205).

Aqui surge um ponto de tensão: a comunhão do interesse do contratante com os resultados de uma pesquisa histórica não pode ser garantida a priori, conforme já indicado desde os anos 1990 por historiadores públicos e orais preocupados com essa questão (Alberti, 1996b; Castaneda, 1999; Mendes, 2010). E se documentos indicarem informaçôes indesejadas pela empresa? E se depoentes relatarem aspectos que não corroborem com a memória institucional pretendida pelos contratantes? Já foi notado uma tendência a um teor laudatório e até mesmo hagiográfico na escrita da história empresarial sob contrato - não somente no Brasil (Clark; Rowlinson, 2004). Seria possível conciliar a expectativa da encomenda com a empiria envolvida na pesquisa histórica?

organizações, que vão da sua natureza jurídica à caracterização de seu corpo de funcionários, ainda que elas ocupem um lugar semelhante no mercado de serviços históricos a empresas. 
Para avaliar essas questóes, propôe-se observar um projeto específico do Museu da Pessoa, com atenção particular às entrevistas, momento em que emerge a história oral. $\mathrm{O}$ livro Educar para ofuturo - Fundação Bradesco 50 anos: 1956-2006, publicado em 2006, foi feito sob encomenda da Fundação Bradesco ${ }^{4}$ e pautou-se em sessenta entrevistas, parte do acervo de livre acesso do Museu. Analisou-se a metodologia empregada nas entrevistas de história de vida, cotejando-as entre si e com a narrativa publicada no livro. O caso emprega operaçôes comuns do Museu da Pessoa, seguindo protocolos historiográficos que reincidem nos outros projetos empresariais da organização. ${ }^{5}$ Assim, considerando-se o Museu como um agente central no meio da história empresarial sob encomenda no Brasil - é associado à Aberje, da qual já recebeu vários prêmios -, entende-se que o estudo de caso proposto pode enunciar frutíferas percepçóes sobre o quadro geral em questão.

\section{0 acesso aos depoimentos}

O Museu da Pessoa possui um razoável número de artigos, livros e manuais em que são estabelecidos seus parâmetros teóricos e metodológicos. ${ }^{6}$ Nessas publicaçóes, nota-se que se alinha à perspectiva de uma história oral de certo engajamento social, enfocando depoimentos de "pessoas comuns" - o que condiz com seu lugar social, o terceiro setor. Assim, buscando manter integridade nos projetos sob encomenda, insistese em conformar os depoimentos envolvidos como patrimônios: as entrevistas devem possibilitar a narraçáo da trajetória de vida singular do entrevistado, captando nela o lugar da instituição contratante (Lopez, 2008); devem ser garantidos, também, um armazenamento seguro e a exposição pública desses depoimentos. É a disponibilização irrestrita desses materiais, afinal, que concretizaria o seu fim público, confirmando o caráter expositivo que justifica o nome de Museu.

A garantia do acesso é uma prerrogativa para o registro no Museu, que comenta que "é essencial que os autores da narrativa (o entrevistado ou o titular de uma foto, por exemplo) autorizem a reprodução e o uso da sua imagem, voz ou texto, bem como sejam esclarecidos quanto ao destino do material por meio de um documento

4 Fundada em 1956, a Fundação Bradesco é a instituição filantrópica do Banco Bradesco. Sua atuação se direciona ao ensino básico e profissionalizante - sendo atualmente o maior projeto de educação privada gratuita no país, presente em todos os estados da federação.

5 Vale notar que trinta e sete profissionais do Museu da Pessoa envolveram-se no projeto - entre coordenação, pesquisa, entrevistas, produção, transcrição, captação de depoimentos, redação final e revisão.

6 Dentre os quais destacam-se História Falada: Memória, Rede e Mudança Social (2005); Memória social: uma metodologia que conta bistórias de vida e o desenvolvimento local (2008) e Tecnologia Social da Memória: Para comunidades, movimentos sociais e instituiçôes registrarem suas histórias (2009). 
de cessão de direitos". Este garante a disponibilização dos registros "para os fins da produção, edição, exibição e comercialização de obras diversas de preservação histórica que venham a ser criadas e/ou produzidas pela Sociedade" (Fundação Banco do Brasil; Museu da Pessoa, 2009, p. 28). Sem embargo, a construçáo de acervos de depoimentos orais e os trâmites contratuais envolvidos na sua disponibilização não são exclusividade do Museu, mas objetos comuns a programas de história oral. No entanto, o fato de afirmar-se explicitamente o interesse na disponibilização desse acervo ao público é importante, pois indica uma primeira inflexáo no tratamento de projetos empresariais.

Das sessenta entrevistas componentes do projeto, três não foram cedidas à realização deste artigo. Naturalmente, se não assinada a cessão de direitos, é inviável a disponibilização dos depoimentos; não há como precipitar conclusôes sobre o assunto. Entretanto, chama a atenção o fato de os depoimentos indisponíveis serem, justamente, de personagens centrais na história da Fundação Bradesco: Lázaro Brandão - à época, presidente da Fundação e do Conselho Administrativo do Banco Bradesco -, Márcio Cypriano - presidente executivo do Banco - e Jarbas Passarinho - ex-Ministro da Educação entre 1969 e 1974, anos de crescimento da Fundação e, também, os chamados Anos de Chumbo da Ditadura Civil-Militar brasileira. Além disso, quando solicitados depoimentos de outro projeto filantrópico-empresarial para realizar comparaçóes - especificamente Investimento Social para a Cidadania, feito para a Camargo Corrêa em 2011 - "por questóes contratuais" nada foi cedido, mas indicou-se que se acessassem acervos de outros projetos, náo empresariais. $\mathrm{O}$ fato de depoimentos de líderes empresariais e de acervos completos de outras empresas estarem indisponíveis, por mais que razóes contratuais pontuais possam o justificar, implica ao menos refletir sobre o compromisso assumido pelo próprio Museu da Pessoa em suas publicaçôes, de tornar público seu acervo - seus manuais, ao menos, náo preveem exceçóes a empresas. Com efeito, é um indício de possíveis inconsistências metodológicas nesses projetos hipótese que ganha corpo quando analisadas as entrevistas.

\section{As entrevistas}

É seguro dizer, como Jean-Jacques Becker (2006, p. 28), que a história oral cria "arquivos provocados", imersos no trabalho dos profissionais entusiastas da produção desses relatos. O Museu da Pessoa se propôs a mobilizar os fundamentos da história oral na criação de um acervo de histórias de vida e em projetos contratados específicos. Se registros individuais teriam as marcas indeléveis de qualquer entrevista, os "provocados" nos projetos empresariais, então, estariam em maior medida respingados de "resíduos de ação", como qualificou Alberti (1996a, p. 3-4). Por um lado, um resíduo da ação interativa entre entrevistador e 
entrevistado, que direciona - mesmo que despropositadamente - a forma como se manifesta a memória do depoente. Por outro, os resíduos da própria memória, que emerge subjetivamente no momento da entrevista.

Analisadas as transcriçóes disponíveis, é possível identificar elementos estruturais comuns nas entrevistas de Educar para of futuro. Trata-se de um roteiro de entrevista de história de vida comumente indicado na maioria dos manuais de história oral: iniciase com perguntas sobre natalidade, nome e profissão dos pais e aspectos da infância; depois, aponta-se à vida escolar e profissional do depoente - momento em que a Fundação Bradesco se torna elemento central. Além disso, questiona-se sobre relaçóes familiares e preferências de lazer. No final, explora-se a importância da Fundação para a educação no Brasil e a opiniáo do depoente em participar do projeto.

Os entrevistados tinham consciência de que seus depoimentos se deviam ao convite da Fundaçáo Bradesco, e foi comum que eles procurassem, o quanto antes, falar da instituição. ${ }^{7}$ A ex-aluna e subgerente departamental, Ana Cleide Souza de Castro (2005), passa rapidamente pelas lembranças da infância, em Olímpia (SP), para descrever a sua experiência como aluna na escola Bradesco de Campinas (SP). Os entrevistadores, atentos ao roteiro, solicitam: "E voltando um pouquinho. Você iniciou os seus estudos como e quando, em Olímpia?". "Vamos voltar um pouquinho?" também é o pedido feito a Alberto Neves da Silva Filho (2006), que já começou tratando do momento em que trabalhava no Bradesco e estudava na escola de Osasco (SP), com dezessete anos de idade. Essa reincidência é uma manifestação do respeito ao princípio da entrevista de história de vida, ou seja, a instituição não seria mais relevante do que as experiências pessoais que não a envolvessem.

No entanto, é possível identificar o interesse por aspectos considerados relevantes no escopo do projeto em questáo, como quando os entrevistadores questionam sobre "algum caso pitoresco" na trajetória do entrevistado - obtendo respostas, naturalmente, diversas. Outra questáo obrigatória inquire a respeito de Amador Aguiar, fundador do Banco e da Fundaçáo Bradesco. Mesmo com aqueles que nunca ou mal o conheceram, os entrevistadores insistem no assunto, como ocorre com Ricardo Rehder Garcia de Figueiredo (2005). Não raramente, os entrevistadores embarcam nas descriçóes dos depoimentos - praticamente unânimes no elogio ao fundador. Em outros casos, chega-se até mesmo a desenvolver perguntas com enunciados insinuantes das respostas desejadas, contradizendo procedimentos metodológicos de história oral já consolidados em manuais há algumas décadas (Alberti, 2013). Na entrevista de Ocyara Almeida dos Santos Soriano (2005), por exemplo, busca-se descrever Aguiar perguntando sobre os "valores dele, você acha que perpassa por tudo, toda...". "Perpetuou", responde a

7 Quarenta e sete depoentes tiveram relação profissional com a Fundação Bradesco: quatro eram funcionários, ex-funcionários ou aposentados do Banco Bradesco; três eram ex-alunos de escolas; e seis foram parceiros ligados à Fundação. 
professora. No depoimento da gerente, Maria Cristina Telles (2006), os entrevistadores incitam comentários bastante positivos sobre o fundador: "Ele foi iluminado, né? Assim...". A resposta, apesar de positiva, é um vacilante "é, acho que sim". A recorrência das perguntas sobre Aguiar resulta no primeiro capítulo do livro, "A inspiração desta história”, uma breve e elogiosa biografia do fundador.

A intercessão dos entrevistadores, em outros momentos, é fortalecida em diálogos amistosos com os depoentes. Encaminhando-se ao final da entrevista de Gilberto Dimenstein (2006), o entrevistador afirma que "a história da Fundação Bradesco traz muito a história de transformação de vida, de transformação social do cidadão", assumindo - corretamente - que o depoente compartilharia da mesma visão. Com expectativa de obter de Ana Cleide de Castro (2005) elementos sobre o legado da Fundação, pergunta-se, dicotomicamente: "A gente percebe pela pesquisa que a Fundação é pioneira em muitas coisas, né?". O "sim" pálido da resposta não agrada aos entrevistadores, que insinuam adjetivos, eles mesmos, à resposta esperada: "Inclusão, cidadania. Você poderia mostrar algumas coisas em que ela se antecipou, algumas pérolas da Fundação, algumas coisas em que ela até serviu de modelo?”. Avaliando o projeto com o ex-aluno Fábio Massahiro Kosaka (2006), formula-se uma longa pergunta, já estampando a resposta ansiada: "E sobre esse projeto, a importância do Projeto Memória 50 anos da Fundação Bradesco, o que é que você acha desse projeto de resgatar toda essa memória, né, através das histórias de vida, porque através das histórias de vida são contadas, né, acontecimentos que muitas vezes não se registra, né, até que se registre...”. Kosaka não vai além: "Com certeza”.

A Fundação Bradesco é descrita pelos entrevistadores como detentora de uma "história de transformação de vida", "pioneira em muitas coisas", marcada pela "cidadania", "inclusáo", recheada de "pérolas" e "modelo". O trabalho do Museu da Pessoa, por sua vez, recebe os gracejos do esforço em "resgatar toda essa memória", iluminando "acontecimentos que muitas vezes náo se registra". O uso de termos elogiosos à Fundação e ao projeto pelos próprios realizadores exponencia as tensôes da condução das entrevistas. Ainda que resíduos de ação sejam virtualmente incontornáveis, o projeto do Museu multiplica e acentua as suas ocorrências, fugindo de protocolos de boas-práticas de entrevista que procuram evitar questôes fechadas ou enunciados tendenciosos. Muitas vezes, coloca-se em primeiro plano a opiniáo dos condutores do projeto, relegando os depoentes a apenas um "acho que sim" ou um "com certeza".

Merece destaque o depoimento de Denise Aguiar Alvarez Valente (2006), neta do fundador, diretora-adjunta da Fundação à época do projeto - do qual foi idealizadora - e virtual herdeira da instituição. A mais longa das entrevistas é a que melhor expressa a relaçáo entre o contratante e o contratado. Aguiar narra a sua atuaçáo profissional, iniciada no final dos anos 1980, como marca de um período de transição e modernização na gestáo institucional e nas balizas pedagógicas das escolas. $\mathrm{O}$ depoimento, em vários momentos, passa a ser um diálogo descontraído, no qual os comentários da diretora 
são concordados e elogiados pelas entrevistadoras, por ela mesma contratadas: "Não, daí... Olha, sabe o quê que é? Educação é difícil, vou te falar...", comenta ela sobre a dificuldade de implantação de mudanças nas escolas (Denise Aguiar Alvarez Valente, 2006). O lamento é amistosamente acolhido pelas entrevistadoras, evocando a confiança do fundador na neta: "Não, o teu avô eu já admirava. Um cara esperto, ele falou: "Então tá, se vira", diz a primeira entrevistadora, logo completada pela colega: "Você está com essa visão". Aguiar aceita a interjeição: "Então tá...”. Fechando, a primeira entrevistadora arremata: "Olha, que bacana, hein?".

Nesses trechos, os papeis de entrevistador e entrevistado se misturam. O rigor metodológico e o apego processual ao roteiro praticamente deixam de existir, na medida em que a cumplicidade de interesses dos envolvidos homogeneíza as expectativas da entrevista. "Eu acho fantástico isso. Aliás, eu acho que é isso, isso também: eu ia te perguntar se isso é o futuro, de repente, amanhá, você ter toda uma cultura empresarial brasileira que se volta para isso de uma forma ou de outra?", elogia a entrevistadora sobre o trabalho da Fundaçáo Bradesco. A entrevistada, claro, concorda: "Olha, acho que é". Trata-se de um padrão paradigmático que rege o andamento de um depoimento que mais parece um diálogo de uma chefia próxima a seus subordinados do que uma entrevista de história oral - em comparação aos demais depoimentos, nos termos metodológicos que o próprio Museu da Pessoa assume para si e em relação a protocolos consolidados sobre a condução de entrevistas.

O impacto do depoimento de Aguiar sobre o projeto é notável. O crédito cedido às representaçôes da financiadora repercute na narrativa final e nas demais entrevistas. Um exemplo é a referência ao profundo desafeto de Aguiar, Joaquim Monteiro, "aquela praga”, que fora superintendente e membro da diretoria da Fundação até o momento da ascensão da neta do fundador. "Dá pra falar o nome desse homem?", perguntam as entrevistadoras após as primeiras críticas de Aguiar. "Dá, Monteiro, pode falar. Eu detesto ele" (Denise Aguiar Alvarez Valente, 2006). Monteiro é citado em outros nove depoimentos, em nenhum momento de forma crítica ou negativa, ao lado de personagens como Carlos de Oliveira, Antônio de Freitas e João Cariello de Moraes Filho, líderes importantes da Fundação - com direito a comporem o rol de depoimentos do projeto. Em nenhum momento os entrevistadores buscam aprofundar o assunto e, ao contrário do que ocorre com seus ex-colegas, o depoimento de Monteiro não foi ouvido para a composição do projeto.

\section{Memórias em disputa}

Frequentemente, suprimem-se da narrativa publicada dados descritos nos depoimentos, poupando as visóes negativas e críticas que eles poderiam suscitar. 
Considerando-se que projetos assim envolvem muitos depoimentos, desenha-se constantemente uma "multiplicidade de memórias em disputa", que se apaziguam no trabalho do historiador, ao tecer uma narrativa que serve de desfecho às tensóes contidas nas memórias de vida que lhe serviram de fonte (Alberti, 1996a, p. 6-7). Esse apaziguamento, entretanto, deve ser fruto de métodos e critérios claros e transparentes: os depoimentos devem ser entendidos como fontes, de modo que a reincidência de informaçóes e o lugar social dos depoentes, por exemplo, devem guiar a configuraçáo da narrativa final. A análise das fontes de Educar para of futuro, entretanto, indica alguns equívocos na metodologia empregada para a escrita do livro.

Uma imagem desse fenômeno é a reincidente questão da disciplina nas escolas da instituiçáo de 1960 a 1980. "O cabelo tinha que ser cortado, o sapato tinha que estar muito bem limpo, a farda tinha que estar muito bem limpa, aquelas filas indianas pra entrar na sala, pra ir embora pra casa, pra pegar o lanche, né?", descreve o exaluno de Irecê (BA), Altair Roberto de Lima (2006), "eu cresci nessa disciplina, né?”. Questionado sobre mais lembranças, ele é direto: "Da Fundação Bradesco eu me lembro de castigos também, que eu sofri”.

Essa rigidez faz alguns depoentes refletirem sobre a proximidade com os preceitos educacionais militares, respaldados pelo governo ditatorial de entáo: "Existia uma influência do Regime Militar em termos das políticas educacionais na época, do modelo educacional na época que era aplicado nacionalmente", explica Antônio Carlos das Neves (2005), ex-aluno e gerente departamental. A ex-aluna de Canuanã (TO), Isabel Ferreira Rocha Lima (2006), confirma essa percepção: "da mesma forma que um aluno do sistema militar tem um diferencial, o aluno da Fundaçáo Bradesco tem um diferencial também. Em termos do compromisso, da competência desse aluno, da disciplina, a organização é outra”. Osório Alves Costa (2006), ex-aluno e inspetor na escola de Conceição do Araguaia (PA), relata que sua irmã foi expulsa da escola após engravidar, no início dos anos 1980. Por não ser casada, ela rompera o código disciplinar da organização. Nesse caso, os entrevistadores não manifestam o interesse pelos "casos pitorescos" de outrora, mesmo em se tratando de um caso singular espontaneamente trazido pelo depoente. Ao contrário, desvia-se para amenidades: "E quando o senhor pegava algum aluno e uma aluna num namorico? Como que era?”. É especulativo determinar o motivo da omissão da temática disciplinar na narrativa publicada - bem como avaliar a veracidade ou não desses parâmetros. Porém, o potencial crítico do tema leva a crer que, se ele náo compôs o livro, foi para preservar a Fundação.

Alinhada ao discurso de intervenção social privada do terceiro setor, a narrativa publicada procura legitimar os preceitos de seus financiadores e executores. Segundo Educar para o futuro, a criação da Fundaçáo, em 1956, ocorrera "enquanto o quadro da educação no Brasil parecia confuso", selando "a promessa que Amador Aguiar fizera a si próprio, anos antes, quando pensara em cuidar, junto com a sua esposa, de crianças e comunidades pobres por todo o Brasil" (Fonseca, 2006, p. 42-43). Enunciada a 
iniciativa de agir apesar da ineficácia do Estado, estabelece-se um padrão descritivo que reforça a inércia do setor público e a eficiência da Fundação. A Lei de Diretrizes e Bases da Educaçáo Nacional (LDB), em 1996, alterava pontos do ensino profissionalizante no país; a Fundaçáo já se antevira há anos com as mesmas práticas (Fonseca, 2006, p. 128). Passou-se a indicar o meio ambiente como tema transversal obrigatório no ambiente escolar em 1999; as escolas Bradesco já o faziam desde os anos 1970 (Fonseca, 2006, p. 147). Para todos os momentos, a fórmula se repete e reforça as diferenças entre o público e o privado, sendo este a "vanguarda educacional do país." (Fonseca, 2006, p. 145).

Esta é também a leitura predominante dos depoentes. "Infelizmente a educação pública está aí, está falida mesmo. É difícil dizer isso, mas é a verdade", lamenta Kátia Regina de Albuquerque (2006). Quando não por espontânea vontade, os entrevistadores questionam os depoentes na expectativa de informaçóes desse teor: "E nesse diferencial, você saberia citar alguma coisa? Por exemplo, 'na minha experiência com o público era dessa maneira, lá [na Fundação] era completamente ao contrário'. Como é que era isso?”, indaga-se à diretora da escola de Teresina (PI), Márcia Maria Sobreira Soares (2006, p. 21). "Você estava falando da escola pública. Você, quando era aluna da Fundação, convivendo com os outros alunos que não eram da Fundação, com seus colegas, você percebia uma diferença da educação, o que você foi mudando?", pergunta-se à Sônia Regina da Silva Costa (2008), que corresponde: "se toda a empresa fizesse o que a Fundação faz, o Brasil estaria bem melhor".

Um número razoável de depoimentos, no entanto, defende que a função primordial da Fundaçáo Bradesco náo era diretamente contribuir com a "consolidação de uma sociedade menos desigual", como descreve o livro (Fonseca, 2006, p. 189). "Olha, pelo que eu me lembre, náo era muito intensa, não [a relaçáo com a comunidade]. Era mais, assim, com os filhos dos profissionais do Banco, era mais essa relação que existia”, comenta Luís Carlos Watanabi Lara (2006). Para outros, o ensino nas escolas estava ligado à expectativa de formar profissionais capacitados para os postos de trabalho das empresas Bradesco. João Cariello de Moraes Filho (2005), ao ser questionado sobre histórias de alunos de destaque, de "transformaçóes de vida", só consegue destacar casos de alunos empregados dentro do Bradesco. Lilian Roques Silva Felipe (2006) detalha que era comum que os três mais bem avaliados alunos das turmas fossem recrutados pelo Banco - informação que se repete em Wellington Strutz (2006), que afirma ter sido um deles, contratado como funcionário em Itajubá (MG).

A descrição de alguns departamentos da Fundação Bradesco confunde ainda mais a asserção da sua finalidade, como o Centro de Treinamento em Artes Gráficas (Cetag) e a Pecuária Planejada (Pecplan). No livro, essas áreas são apresentadas com destaque à estrutura e aos recursos formativos, sem menção a ganhos lucrativos. As fontes do projeto, no entanto, não legitimam essa narrativa: o Cetag fornecia materiais gráficos às empresas Bradesco a nível nacional, além de formar profissionais para alimentar o 
departamento, lembra Marcos Antônio Nálio (2005); a Pecplan, mesmo depois de separada juridicamente da Fundaçáo por razóes fiscais - porque gerava lucro -, seguira como braço da instituiçáo até ser vendida no final dos anos 1990, relata Ricardo Dias (2006). Novamente, a narrativa publicada omite aspectos das fontes, compondo um texto sóbrio em que essas áreas jamais são entendidas como indiretamente lucrativas ao Bradesco.

A relação com representantes do Estado é outro elemento presente nos depoimentos, mas disfarçado na publicação. O terreno da escola de Canuanã (TO), inaugurada em 1973, foi adquirido, segundo os relatos de Moares Filho, Carlos de Oliveira (2005) e Antônio Perez de Freitas (2005), como parte de um negócio com Dante Pazzanese: "o Bradesco entrou com incentivos fiscais pra dinamizar a fazenda" (Freitas, 2005, p. 12). Segundo João Cariello de Moraes Filho (2005), isso fora obra do esforço político de Jarbas Passarinho, à época Ministro da Educaçáo e Saúde. A exdiretora Ana Iza Oliveira de Pinho (2006), celebra a presença do General Médici na inauguração da escola em 1974: "Era só festa, Bagé, essa é a verdade. E foi inaugurada pelo Presidente de República, foi toda a diretoria do banco, na inauguração da escola, foi seu Amador Aguiar, foi seu Mário [Aguiar], entáo foi uma festa na cidade”. Moraes Filho (2005) lembra de outro evento análogo: a homenagem à mãe do General João Figueiredo no nome da escola de Jaboatão dos Guararapes (PE), em 1983. Nenhum desses casos estão na narrativa final. Fala-se em "mudanças políticas na década de 60" (Fonseca, 2006, p. 62), diz-se que o aumento na desigualdade social do período se deveu à maior procura por mão-de-obra qualificada (Fonseca, 2006, p. 54), são citadas as presenças de Tancredo Neves e de José Sarney na inauguraçáo de escolas, ignorando que o mesmo ocorrera com presidentes da Ditadura (Fonseca, 2006, p. 114 e 120).

Independentemente dessas informaçôes serem ou não verdadeiras, há incoerência entre a narrativa final e suas pretensas fontes. Como o Museu da Pessoa afirma que o interesse da organização contratante é central para a realização dos projetos empresariais, a narrativa elogiosa de Educar para o futuro não surpreende - é até esperada se analisada junto a outros livros empresariais comemorativos. No entanto, a própria introdução do livro, que afirma alinhamento com a "ideia de que a história pode ser contada por seus integrantes valorizando-se e reafirmando suas contribuiçôes na trajetória da instituiçáo" (Fonseca, 2006, p. 7), relembra o compromisso com uma história oral de caráter social, atento às pessoas comuns. Com efeito, as interjeiçóes exageradas nas entrevistas e o apagamento de informações recorrentes da versão final não corroboram com essa proposta. O Museu da Pessoa parece querer alimentar duas expectativas ao mesmo tempo: a de entregar uma narrativa alinhada aos interesses da empresa e a de manter o compromisso com uma história oral inclusiva e democrática. A experiência expressa pelo projeto da Fundação Bradesco, entretanto, levanta a questão da efetiva possibilidade de conciliaçáo desses dois intentos. Talvez seja excessivo dizer que se trata de uma contradição em termos, mas, no projeto em especial, a reincidência de equívocos 
metodológicos observada oferece boas razóes para que se sofistique o questionamento sobre os significados teórico e prático do relacionamento entre história oral e empresas.

\section{Considerações finais}

Em 1996, Alberti citou uma matéria da Gazeta Mercantil que propagandeava a empresários uma promessa: o uso da história no gerenciamento empresarial. Em 2015, O Estado de Sáo Paulo falava do mesmo tema, dessa vez indicando que haveria um mercado de histórias institucionais bem estabelecido e que o "historiador corporativo" seria uma das "profissōes do futuro" (Zandonadi, 2015). Somam-se a esses indícios a consolidação de organizaçôes como o Museu da Pessoa, a atuação de tantos "historiadores com CNPJ", como chamou Pedro Telles da Silveira (2020), a ação de pensadores e organismos empresariais e a multiplicação de publicaçôes históricas sob encomenda. No momento em que se regulamenta a profissão de historiador no Brasil, a presença de empresas no seu espectro de atuação é uma realidade, mas ainda faltam reflexões sobre suas implicações práticas e teóricas.

Como o caso do projeto do Museu da Pessoa para a Fundaçáo Bradesco pode contribuir para a reflexão sobre o lugar da história oral na relação história-empresas? O produto do projeto, o livro Educar para o futuro, correspondeu aos anseios da organizaçáo contratante, com "boa qualidade gráfica e ricamente ilustrado", "linguagem agradável e de leitura envolvente", como descreveram historiadoras especialistas nesses serviços (Tonini; Gagette, 2004, p. 120). Mas, e a história oral? O Museu da Pessoa assumiu compromissos com uma história oral de certa militância ao adotar entrevistas de história de vida de pessoas comuns e compor um acervo público alinhado aos pressupostos sociais de uma Oscip. Considerando-se os equívocos metodológicos identificados na conduçáo das entrevistas, bem como o apagamento de certas memórias da narrativa final no livro, pode-se razoavelmente considerar o projeto como falho e decepcionante do ponto de vista da história oral.

Entretanto, deve-se sublinhar que, além do livro, o projeto gerou um acervo oral de livre acesso - ainda que com relevantes exceçóes. Assim, se o Museu não produziu uma narrativa fidedigna às suas pretensas fontes em Educar para o futuro, preferindo um teor laudatório ao gosto do cliente, pode-se dizer que o acervo oral que é fruto do projeto oferece fontes para a escrita de uma outra história da Fundaçáo Bradesco. Com efeito, foi o acesso a esses depoimentos que permitiu este estudo crítico. Por um lado, o Museu entregou o produto contratado, garantindo boa reputação para trabalhos futuros e recursos financeiros para sua sustentaçáo. Como contrapartida, produziu-se um acervo de depoimentos que, mesmo com as suas inconsistências metodológicas, concede acesso público para fontes de um objeto de estudo privado. Nesse sentido, a 
promessa pública da história oral e da razão social empregada na retórica do Museu da Pessoa parece, ao menos parcialmente, cumprida. Mas será o suficiente?

Pequenas incursóes pelo acervo de projetos empresariais já encontram entraves ao acesso de alguns depoimentos, como mencionado. Além disso, os depoimentos do acervo são apenas potenciais fontes para a construção de possíveis histórias empresariais; a narrativa publicada em livro, por outro lado, já existe concretamente, em um texto histórico de caráter propagandístico e silenciador de memórias reincidentes nos depoimentos. Será que somente a possibilidade de acesso a esses depoimentos, em arquivos invisíveis para a maioria das pessoas, compensa a criaçáo e a propagação de narrativas históricas que mais agradam a empresários do que aos preceitos de uma história oral militante, como a reivindicada pelo Museu da Pessoa? Não estariam as empresas aproveitando-se da retórica democrática da história oral para legitimar suas identidades, pautadas no individualismo empreendedor e na desqualificação do setor público?

A precarização das universidades, com cortes de verba para pesquisas e diminuição de concursos, e o lugar secundário que a educação e a pesquisa possuem na agenda de diferentes esferas governamentais no Brasil dos últimos anos, acentua a complexidade do quadro em questáo. Por escolha ou por necessidade, historiadores orais ou não deveráo estarâo cada vez mais em contato com empresas, com todas as pressóes envolvidas nessas relaçóes trabalhistas (Silveira, 2020; Turin, 2018). Consequentemente, fazem-se cada vez mais necessários debates que problematizem o relacionamento entre empresas e a prática histórica. Como visto, as empresas parecem possuir uma ideia clara do que pretendem com essa relação. A história, então, deve avançar sobre as suas próprias respostas para a equação - o que, como mostra o caso do Museu da Pessoa, não é nada simples.

\section{Referências}

ALBERTI, Verena. O que documenta a fonte oral? Possibilidades para além da construçáo do passado." Trabalho apresentado à mesa-redonda "Ouvir e narrar: métodos e práticas do trabalho com História Oral, durante o II Seminário de História Oral promovido pela UFMG em 1996. Rio de Janeiro: CPDOC, 1996a. Disponível em: http://bibliotecadigital.fgv.br/dspace/ handle/10438/6767?show=full. Acesso em: 16 set. 2021.

ALBERTI, Verena. Vender história? A posiçáo do CPDOC no mercado das memórias. Rio de Janeiro: CPDOC, $1996 \mathrm{~b}$.

ALBERTI, Verena. Manual de história oral. Rio de Janeiro: FGV, 2013.

BECKER, Jean-Jacques. O handicap do a posteriori. In: FERREIRA, Marieta; AMADO, Janaína (Org.). Usos \& abusos da história oral. Rio de Janeiro: FGV, 2006. p. 27-32.

CASTANEDA, Christian. Writing Contract Business History. The Public Historian, v. 21, n. 1, 
p. 11-29, 1999.

CLARK, Peter; ROWLINSON, Michael. The Treatment of History in Organisation Studies: Towards an 'Historic Turn'? Business History, v. 46, n. 3, p. 331-352, 2004.

FERREIRA, Marieta de Moraes. Desafios e dilemas da história oral nos anos 90: o caso do Brasil. História Oral, n. 1, p. 19-30, jun. 1998.

FONSECA, Cláudia. Educar para o futuro - Fundação Bradesco 50 anos: 1956-2006. São Paulo: Museu da Pessoa, 2006.

FORMAN, Richard. History inside Business. The Public Historian, v. 3, n. 3, p. 40-61, 1981.

FUNDAÇÃO BANCO DO BRASIL; MUSEU DA PESSOA. Tecnologia Social da Memória: Para comunidades, movimentos sociais e instituiçóes registrarem suas histórias. Sáo Paulo: Museu da Pessoa, 2009.

GONÇALVES, Caroline; SAES, Alexandre Macchione. Surgimento e desenvolvimento da Business History: da História de Empresas à História de Negócios. In: CONGRESSO BRASILEIRO DE HISTÓRIA ECONÔMICA, 12.; CONFERÊNCIA INTERNACIONAL DE HISTÓRIA DE EMPRESAS, 13., 2017, Niterói. Anais... Niterói: UFF/ABPHE, 2017.

JONES, Geoffrey. Debating methodology in business history. The Business History Review, v. 91, n. 3, p. 443-455, 2017.

LOPEZ, Immaculada. Memória social: uma metodologia que conta histórias de vida e o desenvolvimento local. São Paulo: Museu da Pessoa: Senac São Paulo, 2008.

MENDES, José. História Empresarial: da monografia apologética ao instrumento de gestáo estratégica. In: RIBEIRO, Maria Manuela Tavares (Coord.). Outros combates pela História. Coimbra: Imprensa da Universidade de Coimbra. 2010. p. 279-296.

MUSEU DA PESSOA. Museu em números. Museu da Pessoa, São Paulo, 2019. Disponível em: https://www.museudapessoa.net/pt/entenda/museu-em-numeros. Acesso em: 15 set. 2021.

NASSAR, Paulo. Sem memória, o futuro fica suspenso no ar. In: NASSAR, Paulo (Org.). Memória de empresa: história e comunicação de mãos dadas, a construir o futuro das organizaçôes. São Paulo: Aberje, 2004. p. 15-22.

SANTOS, Larissa Conceição dos. História e legitimação organizacional: reflexôes acerca das narrativas histórico-organizacionais. Organicom, São Paulo, ano 11, n. 20 p. 61-72, 2014.

SILVEIRA, Pedro Telles da. O historiador com CNPJ: depressão, mercado de trabalho e história pública. Tempo \& Argumento, Florianópolis, v. 12, n. 30, maio/ago. 2020.

TONINI, Beth; GAGETE, Élida. Memória Empresarial: uma análise da sua evolução. In: NASSAR, Paulo (Org.). Memória de empresa: história e comunicação de mãos dadas, a construir o futuro das organizaçóes. São Paulo: Aberje, 2004. p. 113-126.

TURIN, Rodrigo. Entre o passado disciplinar e os passados práticos: figuraçóes do historiador na crise das humanidades. Tempo, Niterói, v. 24, n. 2, p. 187-205, maio/ago., 2018.

WORCMAN, Karen. Memória do futuro: um desafio. In: NASSAR, Paulo (Org.). Memória de empresa: história e comunicação de mãos dadas, a construir o futuro das organizaçôes. São Paulo: Aberje, 2004. p. 23-32. 
WORCMAN, Karen. "Nossas Memórias, Nossas Histórias": ou de como as bibliotecas podem usar e abusar do Museu da Pessoa, uma grande 'humanoteca'. Palestra ao $10^{\circ}$ Seminário Internacional de Bibliotecas Públicas e Comunitárias, o Biblioteca Viva. Sáo Paulo: Museu da Pessoa, 2017. Disponível em: https://acervo.museudapessoa.org/pt/explore/artigos/nossasmemorias-nossas-historias-ou-de-como-as-bibliotecas-podem-usar-e-abusar-do-museu-dapessoa-uma-grande-humanoteca. Acesso em: 16 set. 2021.

WORCMAN, Karen; GARDE-HANSEN, Joanne. Social memory technology: theory, practice, action. Nova Iorque: Routledge, 2016.

WORCMAN, Karen; PEREIRA, José (Coord.). História falada: memória, rede e mudança social. São Paulo: SESC-SP: Museu da Pessoa, 2006.

ZANDONADI, Viviane. Profissôes do Futuro: historiadores corporativos. O Estado de São Paulo, São Paulo, 22 jul. 2015. Educaçáo. Disponível em: https://educacao.estadao.com.br/noticias/ geral,profissoes-do-futuro-historiadores-corporativos, 1730012. Acesso em: 15 set. 2021.

\section{Fontes orais}

ALBUQUERQUE, Kátia Regina de. [fev. 2006]. Entrevistadores: Damaris do Carmo e Maria Lenir Justo. Ceilândia, DF, 7 fev. 2006.

CASTRO, Ana Cleide Souza de. [dez. 2005]. Entrevistadores: Judith Ferreira e Marlon Chaves. São Paulo, SP, 16 dez. $/ 2005$.

COSTA, Osório Alves. [jan. 2006]. Entrevistadores: Marlon Chaves e Damaris do Carmo. Conceição do Araguaia, PA, 6 jan. 2006.

COSTA, Sônia Regina da Silva. [dez. 2008]. Entrevistadores: dado não informado pelo Instituto Museu da Pessoa. Transcrito por Rodrigo de Godoy. [S. 1.]. [S.d.]. Publicada em 4 dez. 2008.

DIAS, Ricardo. [abr. 2006]. Entrevistadores: Maria Lenir Justo e Damaris do Carmo. São Paulo, SP, 17 abr. 2006.

DIMENSTEIN, Gilberto. [fev. 2006]. Entrevistadores: Judith Ferreira e Damaris do Carmo. Osasco, SP, 10 fev. 2006.

FELIPE, Lilian Roques Silva. [jan. 2006]. Entrevistadores: Marlon Chaves e Damaris do Carmo. Palmas, TO, 9 jan. 2006.

FIGUEIREDO, Ricardo Rehder Garcia de. [jan. 2005]. Entrevistadores: Judith Ferreira e Maria Lenir Justo. Osasco, SP, 3 jan. 2005.

FREITAS, Antônio Perez de. [dez. 2005]. Entrevistadores: Judith Ferreira e Damaris do Carmo. Osasco, SP, 7 dez. 2005.

KOSAKA, Fábio Massahiro. [maio 2006]. Entrevistadores: Damaris do Carmo e Maria Lenir Justo. São Paulo, SP, 30 maio 2006.

LARA, Luís Carlos Watanabi. [mar. 2006]. Entrevistadores: Damaris do Carmo e Maria Lenir 
Justo. Osasco, SP, 17 mar. 2006.

LIMA, Altair Roberto de. [fev. 2006]. Entrevistadores: Damaris do Carmo e Maria Lenir Justo. Ceilândia, DF, 8 dez. 2006.

LIMA, Isabel Ferreira Rocha. [jan. 2006]. Entrevistadores: Marlon Chaves e Damaris do Carmo. Formoso do Araguaia, TO, 11 jan. 2006.

MORAES FILHO, João Cariello de. [dez. 2005]. Entrevistadores: Judith Ferreira e Damaris do Carmo. Osasco, SP, 13 dez. 2005.

NÁliO, Marcos Antônio. [dez. 2005]. Entrevistadores: Marlon Chaves e Judith Ferreira. São Paulo, SP, 6 dez. 2005.

NEVES, Antônio Carlos das. [dez. 2005]. Entrevistadores: Maria Lenir Justo e Judith Ferreira. São Paulo, SP, 14 dez. 2005.

OLIVEIRA, Carlos. [dez. 2005]. Entrevistadores: Marlon Chaves e Damaris do Carmo. São Paulo, SP, 9 dez. 2005.

PINHO, Ana Iza Oliveira de. [fev. 2006]. Entrevistadores: Judith Ferreira e Maria Lenir Justo. Osasco, SP, 6 fev. 2006.

SILVA FILHO, Alberto Neves da. [fev. 2006]. Entrevistadores: Lení Justo e Damaris do Carmo. São Paulo, SP, 21 fev. 2006.

SOARES, Márcia Maria Sobreira. [jan. 2006]. Entrevistadores: Damaris do Carmo e Judith Ferreira. Osasco, SP, 26 jan. 2005.

SORIANO, Ocyara Almeida dos Santos. [dez. 2005]. Entrevistadores: Cláudia Fonseca e Marlon Chaves. Osasco, SP, 6 dez. 2005.

STRUTZ, Wellington. [fev. 2006]. Entrevistadores: Damaris do Carmo e Maria Lenir Justo. São Paulo, SP, 23 fev. 2006.

TELLES, Maria Cristina. [dez. 2006]. Entrevistadores: Maria Lenir Justo e Judith Ferreira. Osasco, SP, 14 dez. 2006.

VALENTE, Denise Aguiar Alvarez. [fev. 2006]. Entrevistadores: Cláudia Fonseca e Damaris do Carmo. Osasco, SP, 1 fev. 2006.

Recebido em 30/01/2021.

Versão final reapresentada em 07/04/2021.

Aprovado em 10/06/2021.

Fonte de financiamento: nada a declarar.

Conflitos de interesse: nada a declarar. 